\title{
1. White-collar crime motivation
}

This chapter addresses the motivational side of financial crime by white-collar offenders. Motives exist in possibilities and threats for individuals and organizations. Motives found in attractive individual economic possibilities and attractive corporate economic possibilities can make crime represent a convenient avenue to achieve ambitions and goals. Motives found in painful individual economic threats and painful corporate economic threats can make crime represent a convenient avenue to avoid collapse and bankruptcy. In addition to these four motivational perspectives, rational self-interest motivation is a fifth perspective, which is independent of the beneficiary of financial crime. The relative convenience of crime determines how needs are met by potential offenders.

In white-collar crime research, a distinction emerges between individuals and organizations as beneficiaries of crime. Therefore, this book makes the same distinction between occupational crime and corporate crime. Self-interested individuals commit occupational crime in their profession against their employers (e.g., embezzlement or receipt of bribes) and other victims (Shepherd and Button, 2019). Organizational officials commit corporate crime in the larger interests of an organization, such as bribing potential customers, avoiding taxes by evasion, and misrepresenting accounting to get unjustified government subsidies.

In motivational research, we can make a distinction between possibilities and threats. Possibilities open up avenues for exploration and exploitation. A more luxurious lifestyle and an improved business performance represent possibilities. Threats represent pain and obstacles that everyone would like to avoid. A less successful lifestyle and the threat of bankruptcy can imply pain and suffering.

The motive for white-collar crime is simply financial gain (Berghoff and Spiekermann, 2018). The motive for financial gain, however, can vary. Crime might be a response to both possibilities and threats, and it might be a response to both strengths and weaknesses. An offense can enable exploration and exploitation of a business or a personal possibility that seem otherwise unobtainable. An offense can enable avoidance of business threats or personal threats. An offense can make the business or the personal situation even stronger, and it can reduce and compensate for business or personal weaknesses. 
A number of perspectives from the research literature can explain white-collar crime motives. I organize the various theoretical explanations in this chapter according to whether or not they focus on individual versus corporate needs, and whether or not they focus on possibilities versus threats.

Motivation represents the reasons for people's actions, desires, and needs. Motivation involves personality and cultural factors that induce individuals to act in ways that neutralize the strong ethical controls of society. Specific cultural factors that lead to crime and criminal behavior include the desire to make a fast buck and the fear of losing what already exists as material wealth (Aguilera and Vadera, 2008).

Motivation is different from, but at the same time linked to opportunity (Steffensmeier and Allan, 1996: 478):

Motivation is distinct from opportunity, but the two often intertwine, as when opportunity enhances temptation. As in legitimate enterprise, being able tends to make one more willing, just as being willing increases the prospects of being able.

This link between motivation and opportunity is part of the convenience triangle where motive, opportunity, and willingness can reinforce each other (Gottschalk, 2019).

\section{ATTRACTIVE INDIVIDUAL ECONOMIC POSSIBILITIES}

Greed is the most acknowledged motive for financial crime by white-collar offenders. Goldstraw-White (2012) defines greed as socially constructed needs and desires that can never be completely covered or contended. Greed can be a very strong quest to get more and more of something, and there is a strong preference to maximize wealth. To outsiders it may seem strange that rich people have such a strong desire to become even richer that they are willing to break the law. However, as the definition indicates, greedy individuals are never happy with what they have, as they desperately want more all the time. Prosperity is not a means, but a goal for greedy individuals. Greed can grow when the organization does not have an adequate reaction (Haynes et al., 2015). Greed is a typical motive for occupational crime where individuals enrich themselves. Greed implies that some people never become satisfied with what they earn or what they own. There is a lack of satisfaction with whatever one has. Greed can be a strong quest to get more and more of something, and there is a strong preference to maximize wealth, as wealth is also a symbol of success. Greed leads to a need for an increasingly larger home, several chalets and summerhouses, a bigger boat, luxurious vacations, and ownership in various enterprises. Greed is a desire among all sorts of people. When there 
are simple possibilities for financial gain to enjoy prosperity, then economic crime can be a convenient action. Both Bucy et al. (2008) and Hamilton and Micklethwait (2006) emphasize greed as the most common cause of criminal acts by white-collar offenders.

The hierarchy of needs is another well-known motive for financial crime by white-collar offenders. Needs start at the bottom with physiological needs, needs for security, social needs, and needs for respect and self-realization. When basic needs such as food and shelter are satisfied, then the person moves up the pyramid to satisfy needs for safety and control over own life situation. Higher up the pyramid, the person strives for self-respect, status, and recognition (Maslow, 1943). While street crime is often concerned with the lower levels, white-collar crime is often concerned with the upper levels in terms of status and success. Most individuals will want to move higher up the pyramid when needs below are satisfied. As far as money or other valuable items can help climbing higher in the pyramid, potential offenders may find white-collar crime convenient if other options to achieve success are more stressful and require more resources. Whether the offender wants more at a certain level or wants to climb to higher levels in the pyramid, financial crime can be a means to the end. For some white-collar criminals, money is the goal of crime. For other white-collar criminals, money is a means to a goal of acceptance, influence, and fame. For example, to achieve acceptance and recognition as a successful businessperson, the enterprise has to grow and make money. Financial success as a businessperson can lead to influence, privileges, and status. Admiration and respect in the elite is a desirable goal for many individuals. If it seems difficult and full of strain and pain to reach such a goal by legal means, illegal means represent an alternative. High-status individuals strive for fulfillment, self-esteem, and esteem from others. As Agnew (2014: 2) formulates it: "crime is often the most expedient way to get what you want" and "fraud is often easier, simpler, faster, more exciting, and more certain than other means of securing one's ends".

Glory and power are important to many in the elite in society. They care about status symbols that cost money. They care about treatment as very important persons (VIPs), having reserved parking spaces, and being preferred customers in prestigious restaurants. They care about flying first class on planes, and they care about staying in suites in hotels. At work, they care about having the corner office on the top floor with a large meeting table and comfortable chairs to show their positions. Visible status symbols in all varieties are often self-perpetuating in power. It is convenient to enjoy privileges and status symbols. Façade and personal reputation are important to take care of to keep their positions in the elite. When their positions in the elite are threatened, then some try to compensate by white-collar crime. 
Many law-abiding members of the elite use their economic prosperity to climb to the top of Maslow's hierarchy of needs. Rich people want respect and reputation as well as status and admiration in the community. One way of achieving status is by giving away money through philanthropic behavior. A philanthropist is someone seemingly without self-interest willing to help the disadvantaged and ignoring financial gain. Words like status, privileges, recognition, fame, and admiration are all associated with both law-abiding as well as criminal white-collar people. White-collar offenders commit economic crime to climb, to remain in, or to avoid falling down the pyramid. Hausman (2018: 383) mentions Samuel Insull as a classic philanthropist among white-collar offenders:

The most visible figure in the holding company movement and its collapse, and indeed, in the entire history of the electric power industry in the United States, was Samuel Insull ... He was instrumental in shaping an industry that brought electric power to millions of people and was a noted philanthropist as well.

In addition to greed and the hierarchy of needs, there are a number of other factors suggested in the research literature, which make white-collar crime relevant for attractive individual economic possibilities. An important factor in many societies is the American dream of prosperity and success (Schoepfer and Piquero, 2006). According to the American dream perspective, the ultimate symbol of success and happiness in life is economic wealth. The ultimate goal for every citizen and the sign of success is to become financially rich. Everyone has the opportunity to climb one's way to wealth, since America is the land of opportunity. Those who fail perceive themselves as failures and may choose illegal means to make the dream come true. The American dream places a dominant emphasis on the accumulation of visible assets, thereby increasing individual crime willingness by a concurrent emphasis on what means are acceptable for reaching desired ambitions (Pratt and Cullen, 2005). The American dream emphasizes single mindedly only economic success, while at the same time society seems to be restricting individuals' access to legitimate opportunities for upward socioeconomic mobility, which, in turn, can result in high levels of criminogenic anomie in society. A high white-collar crime rate finds an explanation in the commitment to the objective of material success as emphasized in the American dream. It is an extreme one-sided emphasis on success in exposed assets (Trahan et al., 2005). Other values, such as relationships, health, and a meaningful job have relatively little or no importance in the American dream perspective.

The American dream perspective can explain climbing up the pyramid by both law-abiding and criminal individuals. The American dream suggests that everyone in America has the possibility of becoming monetarily successful. 
A cause for a high white-collar crime rate is a dedication and commitment to the goal of material success as experienced in the American dream. It is caused by an overemphasis on success in exposed assets (Schoepfer and Piquero, 2006), and it is not matched by a concurrent emphasis on what means are legitimate for reaching desired goals (Pratt and Cullen, 2005). When fewer people experience that they are able to live the American dream by means of law-abiding behavior, then more people will explore alternative avenues to live the American dream.

In an empirical study in Germany, Cleff et al. (2013) identified four motivational factors for white-collar crime. (1) The offender seeks recognition and esteem from others. The offender is typically a narcissistic visionary who seeks constant ego stroking from those around. They employ their professional success and money to glorify further their inflated self-image. (2) The offender seeks security and secure livelihood for their family. (3) The offender seeks fulfillment of social norms. (4) The offender suffers from hedonism where pleasure and intrinsic goods are the primary or most important goals of human life. A hedonist strives to maximize pleasure and a luxurious lifestyle.

Some high-status individuals have a need for acclaim as narcissists (Chatterjee and Pollock, 2017; Zhu and Chen, 2015). If illegal financial gain can help achieve desired acclaim, narcissists might feel entitled to crime (Nichol, 2019). Narcissists exhibit an unusual trust in themselves, believing that they are uniquely special and entitled to more benefits than are legitimately available to them (Ouimet, 2010). A particular version of narcissism is narcissistic identification with the organization, where the offender sees little or no difference between self and the business. Then company money is personal money that can be spent whatever way the narcissist prefers (Galvin et al., 2015). A pervasive pattern of grandiosity, need for admiration, and empathy deficits typifies narcissism. While grandiosity and admiration belong to the motivational dimension of convenience theory (Gottschalk, 2019), empathy deficits belong to the willingness dimension of convenience theory where the offender possesses a sense of entitlement (Nichol, 2019). The offender shows unreasonable expectations to receive and obtain preferential treatments (Zvi and Elaad, 2018).

Financial crime can be justified to restore the perception of equity and equality (Leigh et al., 2010). The equity perspective suggests that an executive or other privileged person compares his or her work efforts to another person or group of persons chosen as reference. A situation evaluated as being without equity will prompt behavior to reestablish equality and to remove the feeling of discomfort. The equity perspective proposes that individuals who perceive themselves as unfairly rewarded will feel distressed and therefore try to restore the perception of equity (Huseman et al., 1987). Executives may choose from one or more different referents - or standards - in determining the equitable- 
ness of their pay (Martin and Peterson, 1987). The organizational setting may influence an individual's equity sensitivity level, as employees with advanced education might develop abstract moral principles differentiating themselves from rules, implementing their own autonomous principles, as well as constructing personal opinions of what is right and what is wrong (Roehling et al., 2010).

\section{PAINFUL INDIVIDUAL ECONOMIC THREATS}

The strain perspective has become one of the leading theoretical explanations for crime (Langton and Piquero, 2007). Strain associated with potential collapse and bankruptcy of an enterprise can trigger tax evasion, corruption, and fraud. The strain perspective argues that a range of factors influence whether individuals cope with strains through crime (Thaxton and Agnew, 2018: 888):

Criminal coping is said to be most likely among those with poor coping skills and resources, little social support, low social control, beliefs favorable to crime, criminal associates, and opportunities for crime.

The strain perspective emphasizes strains and stressors that increase the likelihood of crime, the negative emotions (including anger) resulting from those strains that create pressure for corrective action, and the factors that influence or condition the likelihood of criminal coping (Thaxton and Agnew, 2018).

The strain of survival within diverse opportunity structures, such as in an organizational context, may lead to adaptations of crime, delinquency, and other deviant behavior. The disjunction between goals and means creates strain that an individual wants to overcome. Unrealistic expectations may come from a number of sources, including families, friends, media, life events, and self (Hoffmann, 2002).

Agnew (2005) identified three categories of strain: failure to achieve positively valued goals, the removal of positively valued stimuli, and the presentation of negative stimuli. Strain theory posits that each type of strain ultimately leads to deviance for slightly different reasons. All three types tend to increase the likelihood that an individual will experience negative emotions in proportion to the magnitude, duration, and closeness of stress. Strains most likely to result in crime are those seen as unjust and high in magnitude, associated with low social control, being close in threat and consequence, and creating some incentive to engage in criminal behavior.

Strains are events and conditions that individuals dislike. Strains lead to negative emotions and thereby create pressure for corrective action. Crime is one possible action, which seems attractive to some privileged members of the elite as a means to escape from or reduce strains (Froggio and Agnew, 
2007). The strain of pursuing goals within diverse possibility structures may lead to adaptations such as crime, delinquency, and other deviant behaviors (Hoffmann, 2002). Delinquency results when individuals are unable to achieve their goals through legitimate channels (Agnew, 2012).

Sources of strain include failure to achieve inspiration, to achieve aspiration, and to achieve fair and just outcome. Individuals who suffer such failures that increase their reflected appraisal will tend to commit financial crime because they want to reclaim their power of advantage.

In an empirical study by Langton and Piquero (2007), the authors found that the strain perspective was useful for predicting a select group of white-collar offenses. Using data about convicted white-collar offenders, they examined the ability of the strain perspective to explain white-collar offenses. First, they found that strain was positively and significantly related to financial motivations for offending. Next, they found that individuals reporting higher levels of strain were more likely to engage in types of financial crime with higher complexity. Third, strain relates to negative emotions. Finally, strain among white-collar offenders had a negative relationship to business-type motivations for offending.

Langton and Piquero (2007) suggest measurement of strain among white-collar offenders in terms of events such as:

1. Number of legal marriages, where two or more legal marriages can cause more strain.

2. Neighborhood, where being lower class or lower middle class can cause more strain.

3. Academic performance, where failure to achieve positively valued goals is assumed to imply more strain.

4. Total assets, where less wealth can cause more strain.

5. Total liabilities, where more debts can cause more strain.

6. Employment history, where failure to achieve positively valued goals is assumed to imply more strain.

Offense types can measure levels of white-collar crime that form a hierarchical pattern in terms of their organizational complexity and the harm they inflict (Langton and Piquero, 2007):

1. Low-level white-collar crime such as embezzlement, tax offenses, and credit fraud.

2. Mid-level white-collar crime such as mail fraud, bribery, and false claims.

3. Complex large-scale corporate crime such as antitrust and securities violations. 
By means of logistic regression, Langton and Piquero (2007) attempted to predict crime level by strain factors. They proposed that more strain would lead to higher level of white-collar crime. Overall, however, they found no significant support for this explanation.

Strain has many potential causes. The theory of crime forces suggests that the market is such that the only way to survive is to implement financial practices similar to the ones applied by competitors (Leonard and Weber, 1970). If corruption is the name of the game, every business has to provide bribes to stay in business.

Strain typically occurs in times of economic failure and inability to achieve class status. Strain triggers negative emotional states such as anger, fear, or depression, with anger being potentially the most criminogenic emotion. Of course, not all straining experiences or strained individuals resort to illegitimate coping strategies because there are often available legitimate - but less convenient - coping mechanisms that they could turn to. Different types of strain appear to influence different types of negative affect, which in turn influences whether a potential offender chooses a legitimate or illegitimate coping behavior to adapt to strain. Angry responses to strain seem to increase the likelihood of illegitimate coping while no angry responses to strain appear to decrease the probability of illegitimate coping (Ngo and Paternoster, 2016).

Agnew (2014) introduced the motive of social concern and crime, where there is a desire to help others, and thus moving beyond the assumption of simple self-interest. However, as argued by Paternoster et al. (2018), helping others can be a self-interested, rational action. The self-interest or self-regarding preference and that rationality can imply interest in others' materialism. While the economic model of rational self-interest focuses on incentives and detection risks and associated costs (Welsh et al., 2014), Agnew (2014) suggests that economic crime can also be committed when individuals think more of others than of themselves. An entrepreneur can commit financial crime to ensure that all employees have a job they can return to. A trusted employee can pay bribes to make sure that the company will have new orders to survive in the future. An executive may commit embezzlement to be able to help his adult children to recover after personal bankruptcy. Agnew (2014) believes that social concern consists of four elements, namely that (1) individuals care about the welfare of others, (2) they want close ties with others, (3) they are likely to follow moral guidelines such as innocent people should not suffer harm, and (4) they tend to seek confirmation through other people's actions and norms. That a person puts others before oneself will initially lead to less crime. However, economic crime may be committed where the welfare of others and their success is the motive. TenEyck and Barnes (2019) tried to test the association between Agnew's social concern and criminal behavior. 
Painful individual economic threats include the fear of falling from a high-status position in society. Many top executives and other members of the elite in society have a fear of falling from their positions (Piquero, 2012). The fear of falling perspective suggests that the motivation for financial crime by white-collar offenders is the fear of losing what one has worked so hard to achieve. The offender has worked intensively over many years to create the business and to receive the recognition and prestige that goes with success. The fear of losing and falling from grace can stimulate illegal behavior to survive as a member of the elite in society. Crime motivation increases in order to maintain privileged positions. The fear of falling perspective suggests that people in leading positions are afraid of the consequences of failure and therefore try to survive in their privileged positions by applying various means. They are afraid of falling off the financial cliff and losing their wealth and status that goes with it. Therefore, they work constantly hard to remain successful, preferably more successful than others are, while not having the time to relax and enjoy their wealth because of their fear of failure. This struggle for financial success and the maintenance of that success are important to them. The fear of falling leads to criminal outcomes in different times characterized by acute illiquidity or sales decline. The fear of falling contributes to the convenience of white-collar crime in the organizational setting.

Kouchaki and Desai (2015: 362) found that the threat of falling might lead to unethical behavior:

Perceived threat engenders self-protective defenses that cause people to focus narrowly on their own needs, which interfere with adherence to moral principles and encourage unethical acts.

Kouchaki and Desai (2015) suggest that people experiencing anxiety, nervousness, and worry are likely to behave selfishly and engage in self-interested unethical acts in an effort to protect the threatened self. Individuals experiencing threats tend to focus inward and acquire resources as a means of compensating for threats. In threatening situations, the brain tends to shift into a state that facilitates mobilization of defense mechanisms. Threats imply the salience of risk of loss. Threats tend to bring about socially undesirable actions geared toward self-protection. To cope with threat, people rely on a variety of potential mechanisms to shield themselves from negative experiences and unpleasant feelings, and ultimately to protect their self-esteem.

Not all members of the elite are as successful as they would like to be. Some feel that they lack resources and thus the ability to achieve their ambitious goals. They blame the system rather than themselves for their lack of success, and they compensate by white-collar crime (Wood and Alleyne, 2010). 
The perspective of loss aversion states that the disutility of giving up an object is greater than the utility of acquiring one (Nichol, 2019). Organizational death in the form of bankruptcy does not only cause a fall from grace that entrepreneurs and executives are desperate to avoid. Job loss as a consequence of bankruptcy also makes individuals lose their worth in others' eyes, lose a means of organizing their time, lose the companionship of their co-executives, lose their status and titles, lose their dreams, lose an era in their lives, lose a place in their communities, and lose an office to visit every day. Loss of self-esteem is a typical consequence of organizational failure (Crosina and Pratt, 2019).

\section{ATTRACTIVE CORPORATE ECONOMIC POSSIBILITIES}

In many organizations, ends justify means (Campbell and Göritz, 2014). If ends in terms of ambitions and goals are difficult to realize and achieve in legal ways, illegal means represent an alternative in many organizations (Jonnergård et al., 2010). Among most executives, it is an obvious necessity to achieve goals and objectives, while it is an obvious catastrophe failing to achieve goals and objectives. Welsh and Ordonez (2014) found that high performance goals cause unethical behavior. Dodge (2009: 15) argues that it is tough rivalry making executives in the organization commit crime to attain goals:

The competitive environment generates pressures on the organization to violate the law in order to attain goals.

Individual executives would like to be successful, and they would like their workplace to be successful. Being associated with a successful business is important to the identity of many executives. They explore and exploit attractive corporate economic possibilities in both legal and illegal ways, so that their organization can emerge just as successful, or as even more successful, than other organizations. Profit orientation becomes stronger in goal-oriented organizations whose aim tends to be an ambitious financial bottom line.

When an organization develops and maintains a strong systematic socialization program, employees not only identify with the organization but also its goals. When personal promotion or dismissal, as well as bonuses and benefits link directly and individually to the achievement of goals, then employees identify even more strongly with organizational goals. When the socialization process couples tightly to strong accountability systems, employees perceive individually oriented regulation to achieve organizational goals. The pursuit of goals does not at all imply the absence of crime. The bottom-line focus within an organizational context might increase the frequency of financial crime on behalf of the organization for profit or enhancement. A strong emphasis on 
goal attainment might indeed lead organizational members to engage in illegal acts (Kang and Thosuwanchot, 2017).

Incentive systems such as bonus arrangements can lead to white-collar crime such as corruption to meet sales targets or other targets on which bonus payments depend. Alternatively, the offender can pretend to have met targets by manipulating accounting (Nichol, 2019: 329):

Bonus contracts have come under a great deal of criticism in the past few years for creating incentives that encourage managers to manipulate accounting information in order to maximize their pay. Such manipulation can range from subtle earnings manipulation to outright fraud.

When executives perceive high performance goals as invariable, personal desperation for goal achievement can result (Kuvaas et al., 2016: 401):

Perceiving goals as invariable refers to the extent to which employees believe that the goals in a performance management system represent absolute standards that they must meet without exception, even if they think other factors are more important.

Corporations enter into exchange relationships with other corporations that may be suppliers, customers, banks, and consultants. Exchanges can be thought of as discrete events nested within continuous relationships that are developing and changing over the course of time. Central to exchange theory is the transfer of resources between two entities, with a resource being something that another entity values. Reciprocity such as kickbacks are natural according to expectations in an exchange relationship (Huang and Knight, 2017).

An organization is always looking for attractive corporate economic possibilities. Profit-driven crime is a result of a desire for more gain (Naylor, 2003). We thus develop an understanding of profit-driven crime in mainly economic rather than in sociological terms. The profit-driven crime perspective suggests a typology that shifts the focus from actors to actions. Rather than focusing on profit-driven crime as a logical sequence of actions, it deconstructs the crime into its inherent characteristics, which differ radically according to whether an offense is predatory, market-based, or commercial in nature. Among the principal characteristics are whether transfers of property occur by force, free-market exchange, or fraud; whether those transfers involve redistribution of wealth, distribution of income, or redistribution of income; and whether the crime occurs in a non-business, underground network or legitimate business setting. The profit-driven crime perspective answers the how-question, rather than who-question or why-question concerned with white-collar crime.

In Naylor's (2003) perspective of profit-driven crime, predatory offenses involve redistribution of existing legally owned wealth from one party to 
another. Market-based offenses involve evasion of regulations, taxes, and prohibitions. Commercial offenses involve illegal methods to distribute goods and services. Predatory crime involves the illegal redistribution of existing wealth, market-based crime involves the illegal earning of new income, and commercial crime involves the illegal redistribution of legally earned income.

Wealth refers to a stock of assets that accumulates or deteriorates over time, and wealth measurement takes place at a specific point in time. On the other hand, income refers to a flow of value per unit of time. Predatory crime is crime purely of redistribution of existing wealth. Examples include bank fraud and embezzlement. Market-based crime is crime of distribution of new income. Examples include tax evasion and environmental pollution.

Exploitation of attractive corporate economic possibilities can cause environmental pollution.

An example is the oil exploitation in the Gulf of Mexico that caused serious environmental pollution. British Petroleum (BP) operating the Deepwater Horizon platform faced criminal charges amounting to US\$4 billion because of environmental crime. A federal court in New Orleans sentenced BP to pay the record sum (Müller, 2018).

Commercial crime is crime of illegal methods. Examples include corruption and cartel pricing with competitors. One cartel pricing approach is to agree among cartel members on who is next in line. That business provides a very expensive offer to the customer. The other cartel members provide offers as well, but they price their offers even higher than the business that is next in line (Goncharov and Peter, 2019).

Bribery descriptions include "grease in the wheels of commerce" that causes offenders to allocate their resources to the most profitable activities (Cuervo-Cazurra, 2016: 40):

Corruption is usually seen as sand when it is the government official who demands the bribe, but it is usually seen as grease when it is the manager who offers to pay a bribe to get something that helps the company.

Convenience theory emphasizes that a white-collar offense is a crime-by-choice, where legal means less conveniently might enable satisfaction of needs. Convenience theory stresses that there are always alternatives to crime (Gottschalk, 2019). The theory thus contradicts one part of Berghoff and Spiekermann's (2018: 291) definition of white-collar crime, where white-collar crime is an illegal act "to secure financial returns that cannot be collected by legal means". While sometimes almost impossible, there will always be avenues available for legal paths to reach goals in more stressful and painful ways. 


\section{PAINFUL CORPORATE ECONOMIC THREATS}

Markets with crime forces can represent painful corporate economic threats. In many markets, there are cartels that regulate the supply side. A cartel is an implicit agreement between firms in the same industry to fix prices, to divide customers and markets among themselves, to fix industry outputs, to allocate territories, or to divide profits (Goncharov and Peter, 2019: 152):

Cartel members seek to act collectively, as if they were a single monopolist, thereby maximizing the collective profit. By doing so, cartels violate competition policy and severely reduce consumer welfare through price-fixing activities that increase the price of goods far beyond the competitive level. Recent evidence shows that the average price overcharges by cartels prosecuted by U.S. and EU cartel authorities were 48.4 and 32.2 percent, respectively.

Supply to some customers occurs only from some vendors, while supply to other customers occurs only from other vendors in the cartel. There is only symbolic competition between vendors as far as they all seem to offer their products to all potential customers. Cartel members agree not only on market division but also on prices to various customers. When a public procurement officer asks for offers from all potential vendors, they may all provide an offer. However, they have agreed who is next by determining the relative price offer among themselves. The vendor next in line provides an expensive offer to the public procurement officer, while the remaining vendors provide offers that are even more expensive to the public procurement officer.

Being a member of a cartel is illegal in most countries, yet they exist all over the world. Trying to operate outside a cartel in an industry can be painful and impossible to survive. To stay in the industry, businesses have to adapt to the usual way of business in markets with crime forces (Leonard and Weber, 1970). In some markets, there is no other choice but to break the law. If a cartel completely dominates a market, then a new entrant may perceive no other choice but to join the cartel and cooperate with others on price fixing and other illegal activities. The market is such that the only way to survive is to implement financial practices similar to the ones applied by competitors. If corruption is the name of the game, every corporation in the industry has to provide bribes to stay in business.

Leonard and Weber (1970: 408) argued that researchers pay too little attention to market forces as a reason for criminal behavior:

Insufficient attention has been focused by sociologists on the extent to which market structures - that is, the economic power available to certain corporations in concentrated industries - may generate criminal conduct. 
Threats in the workplace may stem from specific market conditions and market forces. Some business enterprises can be so dominant in an industry that others may only survive through economic crime. The threat of losing everything they have built up by working very hard over a long period may cause owners who once were entrepreneurs to intervene and commit VAT fraud and tax evasion in order to prevent their empire collapsing. The alternative for the former entrepreneurs can be bankruptcy crime by removing all assets before bankruptcy so that creditors receive little or nothing. The purpose is to protect the economic interests of the business (Blickle et al., 2006) and possibly start up again without debts.

Threats can come from a monopoly, where potential competitors have the choice either to commit crime or to join the monopoly (Chang et al., 2005). When competitors have formed a cartel, an emerging business may have the choice either to join the illegal collusion or to go bankrupt. Economic balance, preferably excess, is a requirement in the end to survive in all kinds of markets (Brightman, 2009).

Financial motives of white-collar criminals can find explanations in typologies of offenders. Geest et al. (2017: 547) make a distinction between crisis responders, opportunity takers, opportunity seekers, and stereotypical criminals:

Crisis responders are low-frequency offenders who commit white-collar offences typically in response to a crisis occurring in their personal or professional life (for example, financial pressures or pressures from colleagues). Few have multiple convictions for other offences and typically, these offenders lead ordinary and law-abiding - though at times troubled - lives. They often own or manage small businesses that provide them the means to commit white-collar crime. The second group of offenders is called opportunity takers. To them, committing an offence is equally unusual. Yet, unlike crisis responders, their key motivation to engage in white-collar crime is to take advantage of a specific opportunity. They typically commit only one or two white-collar offences, and only when the chance arises. Crisis responders and opportunity takers constitute the bulk of white-collar offenders. Both are distinct from a third group of offenders, which is labelled opportunity seekers. This group of offenders actively seeks out opportunities to commit an offence. Despite characteristics of conventionality, they typically follow a more chronic - though intermittent - criminal career that spans multiple convictions. The fourth and final group of offenders is a small group of stereotypical criminals. Their white-collar offences are part of a mixed and high-frequent criminal career. Their profile is very similar to that commonly found in the general offender population: their personal lives reflect disadvantage, they often have experienced academic failure, and they show unstable employment careers.

While crisis responders react to painful corporate economic threats, opportunity takers and opportunity seekers react to attractive economic possibilities. 
Threats can create moral panic. Moral panic can characterize reactions that do not accurately reflect the real danger of a threat. During a moral panic, sensitization processes generate an escalation in the individual disturbance (Kang and Thosuwanchot, 2017).

Chattopadhyay et al. (2001) studied organizational actions in response to threats. They found that threats are associated with urgency, difficulty, and high stakes. Threats involve a negative situation in which loss is likely and over which one has relatively little control.

A possibility implies a positive situation in which gain is likely and over which one has a fair amount of control, while at the same time being characterized by urgency, difficulty, and high stakes (Chattopadhyay et al., 2001).

In conformity with the managerial perspective in business literature which highlights the role of managers as agents in deciding enterprise strategies and operations (Lopez-Rodriguez, 2009), as well as leading the activities required to implement corporate priorities, managers can develop and implement both legal and illegal strategies. Managers' perceptions and interpretations determine their commitment to certain goals over other goals (sub-goals). The goal of business enterprises is to make a profit, where enterprises often have the choice between legal and illegal means. Strong and ambitious goal orientation in competitive markets can lead to a strategic choice of white-collar crime. We understand profit-driven crime by both legal and criminal business enterprises mainly in economic rather than sociological or criminological terms. The amounts involved can be staggering (Menon and Siew, 2012).

\section{RATIONAL SELF-INTEREST MOTIVATION}

Both individual and corporate responses to possibilities and threats can result from rational self-interest. The economic perspective is concerned with the influence of rational self-interest in explaining the development of white-collar crime (Pillay and Kluvers, 2014). The economic model of rational self-interest is all about weighing up the pros and cons of alternative courses of actions. The model considers incentives and probability of detection (Welsh et al., 2014). This applies to both private and professional life. Human behavior finds motivation in the self-centered quest for satisfaction and avoidance of suffering (Hirschi and Gottfredson, 1987).

The economic model implies that white-collar individuals pursue their goals, make trade-offs between likely consequences and select actions from several available options. When crime is attractive as a means to fulfill desires and satisfy needs, a rational actor chooses that option. The white-collar individual assesses the benefits and costs, where crime is the preferred option if the benefits of crime exceed the costs of crime, and crime is more attractive than non-crime activities. The damage suffered by the individual in case of 
detection multiplied by the perceived probability of detection is an element of the costs of crime. Since the perceived probability of detection usually is very low, the costs associated with crime are also very low.

Because the economic model implies that crime can be a rational choice, the crime rate will be lower where potential offenders subjectively perceive the risk of detection to be greater, and where the punishment is stricter (Pratt and Cullen, 2005). Rational choice theorists have taken a position that assumes that the standard economic theory of individual preferences will determine whether crime is committed. The greater benefits of crime and the less costs of crime, the more attractive it is to commit criminal acts. According to Berghoff and Spiekermann (2018: 293), potential white-collar offenders "act on cost-benefit calculations involving the expected utility, the likelihood of being caught, and punishment costs".

However, Kamerdze et al. (2014) argue that impulses, emotions, and feelings play a role in individuals' preferences and utility functions, and therefore are relevant to the theory of rational choice, because impulses, emotions, and feelings affect cognitive processes of decision-makers. For example, the feeling of discomfort may prevent a white-collar person from committing crime, even if he or she has a great need for financial gain to achieve personal goals and/or objectives for the business.

The economic model of rational self-interest does not imply that every individual in the same situation will conclude and act in the same way. There will be different choices in the same situation because rationality is a subjective matter. For example, the objective detection risk will be the same in the same situation for everyone, while the subjective detection risk will vary with individual variation in risk perceptions, risk willingness, and risk aversion (Berghoff and Spiekermann, 2018: 293):

Risk-averse people seldom, if ever, violate criminal laws. On the other hand, those who are risk-tolerant or even risk-seeking, i.e. who display fundamental characteristics of entrepreneurial personalities, are much more likely to become criminals.

A person with high risk willingness and low risk aversion will tend to perceive the detection risk as very low, while a person with low risk willingness and high risk aversion will tend to perceive the detection risk as not so low. Research suggests that there is a gender gap in terms of subjective detection likelihood. For example, women tend to have a stronger belief in speed control when driving on the highway. Therefore, men tend to drive faster than women do on the highway because men believe speed control is less likely. The explanation for why women more often adhere to speed limits is thus not necessarily that they prefer to be more law-abiding than men are. 
The economic model of rational self-interest has many factors that influence the decision whether or not to violate the law. An interesting factor is the extent of economic benefits after disclosure, sentencing, and prison. If a potential criminal expects that asset recovery agencies are able to track down illegal financial gain, recover it and confiscate it, there is little to look forward to after incarceration and release from prison. On the other hand, a potential criminal can calculate that a five-year prison stay will make an annual salary of two hundred thousand dollars if one million dollars are waiting when released from prison. Especially for white-collar criminals with greed as their main motive, concealment of financial gain is critical in the case of crime disclosure. Therefore, many white-collar criminals invest large efforts to hide and conceal illegal financial gain both to avoid detection and to avoid confiscation. Tax havens and faithful family and friends are means to succeed in such efforts. On the other hand, law enforcement is committed to confiscating most profits from economic crime in terms of asset recovery. If law enforcement largely succeeds in terms of recovery of illegal profits, then the economic model suggests that the tendency to commit crime will decline among white-collar people. An interesting example is Norway, where recent legislation has changed the burden of proof. Earlier, law enforcement had to prove that assets were acquired in illegal ways. Now, convicted individuals and firms have to prove that assets stem from legal activities. If they are unsuccessful in providing such proofs, then public authorities will confiscate assets.

If the individual assesses economic crime as an attractive action in the form of gain now (profit for realization of current ambitions) compared to possible future cost (punishment, isolation, loneliness), and the individual prefers to avoid the use of more time and effort to solve problems preventing realization of ambitions, then convenience theory says that crime will occur (Gottschalk, 2019). White-collar crime is not emotional or spontaneous abuse of power and influence. Rather, white-collar offenders calculate benefits, costs, and risks in advance of action. The choice of an illegal action is a consequence of a selection of a convenience solution to a challenge or a problem.

The perspective of rational self-interest suggests that people who commit crime do so after considering risks of detection and punishment (risk assessment) to be less important to them than rewards (financial gain) of completing criminal acts successfully. Persons who do not commit crime decide that completing the act successfully is too risky and not worth the benefits (Lyman and Potter, 2007). In other words, if the rationally expected utility of an action clearly outweighs the expected disadvantages resulting from the action, thereby leaving some net material advantage, then every person will commit the offense in question (Blickle et al., 2006).

The rational choice perspective suggests that humans are selfish, focused on achieving their own individual happiness directly or indirectly by the enjoy- 
ment of helping others. Happiness is to many people the highest moral purpose of rational existence. Altruism, in contrast, is thus irrational and determinative of undesirable outcomes. Here, sacrifice is the antithesis of rationality, where the individual surrenders the right to the wrong, good to evil. Self-interest finds its defense in the rational choice perspective by contrasting it with irrational sacrifice (Barry and Stephens, 1998).

The rational choice perspective adopts a utilitarian belief that the economical individual is a reasoning actor who weights means and ends, costs and benefits to make a decision whether or not to commit white-collar crime. For example, increase in detection rate will cause decrease in crime rate (Hefendehl, 2010).

Rational choice by individuals documents itself by individuals' actions and by their reactions to others' action. White-collar crime can be both an act of actions as well as an act of reaction. The anticipated utility determines the choice individuals make by the subjectively expected utility, viewed as an indication of individuals' beliefs and preferences that alternative behavioral strategies are expected to produce.

The perspective of rational self-interest adopts a utilitarian belief that the economical individual is a reasoning actor who weights means and ends, costs and benefits to make a decision whether or not to commit white-collar crime. Utility theory suggests that a criminal will attempt to maximize the utility from criminal behavior. An expected utility maximizing criminal commits an illegal act and, if he or she is neither caught nor punished, increases personal or organizational wealth.

In summary, this chapter has documented that greed is not the only motive for financial crime by white-collar offenders. Sometimes, the motive is removal of strain and pain, and the fear of falling from position. Other motives include the perspective of business ends justifying means in goal orientation, the desire to help others as social concern, an unusual way of business in markets with crime forces such as cartels, and the desire to restore a perception of equity and equality. Crime can be convenient to satisfy greed, remove strain and pain, avoid falling, and achieve other desired outcomes. 